American Journal of Applied Sciences 2 (13): 61-68, 2005

ISSN 1546-9239

(C) 2005 Science Publications

\title{
Irrationality in the Neoclassical Definition of Rationality
}

\author{
Steve Keen \\ University of Western Sydney and Russell Standish, University of New South Wales
}

\begin{abstract}
In this study we are not arguing that competition as it actually occurs in practice is not socially beneficial. Our criticism is directed instead at the false belief that rational profit-maximizing behavior and competition as defined by neoclassical economic theory will lead to a welfaremaximizing outcome-again, as defined by neoclassical theory.
\end{abstract}

Keywords: Marshall, Cournot-Nash style competitive behavior, game theory, irrationality, complex behavior/dynamics

\section{INTRODUCTION}

Critics of neoclassical economics frequently reject the concept of "rational economic man", arguing that this hyper-rational construct is not a suitable model for human behavior. In this study, we take the very different tack of arguing that the neoclassical definition of rational behavior, at least as it applies to profitmaximizing firms, is itself irrational. We derive the formula for truly rational profit-maximizing behavior and then quantify the degree of irrationality needed to achieve the market-level welfare-maximizing outcomes that are the standard fare of neoclassical theory.

Our paradoxical conclusions are (a) that if firms are truly hyper-rational, their behavior will not lead to the welfare-maximizing outcomes predicted by standard neoclassical analysis but to the so-called "monopoly" outcome; (b) that rational analysis leads to the conclusion that Cournot-Nash style competitive behavior is counterproductive and therefore not worth undertaking; and (c) that rather than rationality leading to welfare maximization, a degrees of irrationality is required, which we quantity using multi-agent simulations.

Integrating (and correcting) Marshall and Cournot: The Marshallian and Cournot-Nash game-theoretic approaches to competition reach the same end proposition-that competitive markets will set price equal to marginal cost-from two contradictory starting points. A key presumption in Marshallian analysis is "atomism"-that firms do not strategically react to the hypothetical behavior of other firms. In mathematical notation, atomism is the assumption that $\frac{\partial q_{i}}{\partial q_{j}}=0 \forall i \neq j$.

A key proposition in Cournot and game theoretic analysis is precisely the opposite: That firms do consider the possible responses of other firms when making their output decisions.

It is highly unlikely that the same conclusion can arise from two contradictory assumptions: one must in fact not lead to its alleged conclusion. We show that Marshallian analysis is at fault and compare it to Cournot's analysis, by deriving an accurate profit maximizing formula incorporating the strategic reaction of one firm to another. We start from the assumption that $\frac{\partial \mathrm{q}_{\mathrm{i}}}{\partial \mathrm{q}_{\mathrm{i}}}=\theta \forall \mathrm{i} \neq \mathrm{j}$, where $\theta$ can take on any value (and of course $\frac{\partial q_{i}}{\partial q_{i}}=1$ ).

The true profit maximization condition in a multifirm industry is that profit is maximized where the total derivative of profit equals zero. This is even though-or rather especially because-firms cannot control the behavior of other firms in the industry:

$\frac{\mathrm{d}}{\mathrm{dQ}}\left(\mathrm{TR}\left(\mathrm{q}_{\mathrm{i}}\right)-\mathrm{TC}\left(\mathrm{q}_{\mathrm{i}}\right)\right)=0$

Since $Q=\sum_{j=1}^{n} q_{j}$, this total differential can be expanded to:

$$
\sum_{j=1}^{n}\left(\frac{\partial}{\partial q_{j}}\left(T R\left(q_{i}\right)-T C\left(q_{i}\right)\right) \frac{d q_{j}}{d Q}\right)=0
$$

Assuming that $\frac{\mathrm{dq}_{\mathrm{j}}}{\mathrm{dQ}}=\varepsilon \neq 0 \forall \mathrm{j}$ we derive:

$$
\varepsilon \times \sum_{j=1}^{\mathrm{n}}\left(\frac{\partial}{\partial \mathrm{q}_{\mathrm{j}}}\left(\mathrm{Pq}_{\mathrm{i}}-\mathrm{TC}\left(\mathrm{q}_{\mathrm{i}}\right)\right)\right)=0
$$




$$
\sum_{j=1}^{n}\left(P \frac{\partial}{\partial q_{j}}\left(q_{i}\right)+q_{i} \frac{\partial}{\partial q_{j}}(P)-\frac{\partial}{\partial q_{j}}\left(T C\left(q_{i}\right)\right)\right)=0
$$

Given $\frac{\partial \mathrm{q}_{\mathrm{i}}}{\partial \mathrm{q}_{\mathrm{i}}}=\theta \forall \mathrm{i} \neq \mathrm{j}$ and $\frac{\partial \mathrm{q}_{\mathrm{i}}}{\partial \mathrm{q}_{\mathrm{i}}}=1$, the first term yields $\theta \mathrm{P} \mathrm{N}-1$ times and $\mathrm{P}$ once. The second term can be expanded to:

$$
\mathrm{q}_{\mathrm{i}} \sum_{\mathrm{j}=1}^{\mathrm{n}} \frac{\partial}{\partial \mathrm{q}_{\mathrm{j}}}(\mathrm{P})=\mathrm{q}_{\mathrm{i}} \sum_{\mathrm{j}=1}^{\mathrm{n}} \frac{\mathrm{dP}}{\mathrm{dQ}} \frac{\partial \mathrm{Q}}{\partial \mathrm{q}_{\mathrm{j}}}
$$

where, of course $\frac{\partial Q}{\partial q_{j}}=1$. Substituting and introducing $\operatorname{MC}\left(\mathrm{q}_{\mathrm{i}}\right)$ gives us the general profit-maximization rule for the individual firm in an $n$-firm industry:

$$
(n-1) P \theta+P+n q_{i} \frac{d P}{d Q}=M C\left(q_{i}\right)
$$

It is now easily shown that Marshallian analysis is false. Setting $\theta=0$ reduces (6) to:

$$
P+n q_{i} \frac{d P}{d Q}=M C\left(q_{i}\right)
$$

where, $\quad \mathrm{nq}_{\mathrm{i}} \frac{\mathrm{dP}}{\mathrm{dQ}} \rightarrow \mathrm{Q} \frac{\mathrm{dP}}{\mathrm{dQ}}<0 \quad$ as $\quad \mathrm{n} \rightarrow \infty$. Since the aggregation rule for marginal cost is that $\mathrm{MC}\left(\mathrm{q}_{\mathrm{i}}\right)=$ $\mathrm{MC}(\mathrm{Q})$, the individual firm output level is decided on the same basis independent of the number of firms: given atomism, the market output level for a "competitive" industry is the same as that for a monopoly.

$$
\begin{gathered}
\text { Using } \quad \mathrm{q}_{\mathrm{i}} \frac{\mathrm{dP}}{\mathrm{dQ}}=-\frac{\mathrm{P}-\mathrm{MC}\left(\mathrm{q}_{\mathrm{i}}\right)}{\mathrm{n}} \\
\left(\mathrm{P}+\mathrm{q}_{\mathrm{i}} \frac{\mathrm{dP}}{\mathrm{dQ}}\right)-\mathrm{MC}\left(\mathrm{q}_{\mathrm{i}}\right)=-\left((\mathrm{n}-1) \mathrm{q}_{\mathrm{i}} \frac{\mathrm{dP}}{\mathrm{dQ}}\right) \text { from (6) when } \theta
\end{gathered}
$$

$=0$, we can express (7) in terms of the marginal revenue and marginal cost. This shows that the true profit maximization rule for the individual firm-in the absence of strategic interaction-is not to equate marginal revenue and marginal cost, but to maintain a gap between them:

$$
\operatorname{MR}\left(q_{i}\right)-\operatorname{MC}\left(q_{i}\right)=\frac{n-1}{n}\left(P(Q)-M C\left(q_{i}\right)\right)
$$

Marshallian analysis falsely proposes that $\frac{\partial}{\partial q_{j}}(P)=0^{[1]}$, when in $\operatorname{fact} \frac{\partial}{\partial q_{j}}(P)=\frac{d P}{d Q} \frac{\partial Q}{\partial q_{j}}=\frac{d P}{d Q}$; effectively, it omits the crucial third term from the LHS of (8) when considering "competitive" industries, but includes it when considering a monopoly. This establishes Keen's critique of Marshallian analysis.

If, on the other hand, $\theta=\frac{1}{\mathrm{nE}}$ where $\mathrm{E}$ is the market elasticity of demand $\left(\mathrm{E}=\frac{\mathrm{P}}{\mathrm{Q}} \frac{\mathrm{dQ}}{\mathrm{dP}}\right)$, we recover the game theoretic "best response" $\operatorname{MR}\left(\mathrm{q}_{\mathrm{i}}\right)=\mathrm{MC}\left(\mathrm{q}_{\mathrm{i}}\right)$. As Stigler $\operatorname{argued}^{[1]}$, this behavior leads to price converging to marginal cost as the number of firms increases; but as the next section shows, this clearly is not "profitmaximizing" behavior.

Analytic results: Comparison: An individual firm's maximum profit can be mapped as a function of the average interaction parameter $\theta$. The impact of interaction on profits is starkly illustrated by the example of an industry with a linear market demand curve $P(Q)$ a-bQ and $n$ identical firms with constant marginal cost $c$. The profit-maximizing output level for the $i^{\text {th }}$ firm as a function of $\theta$ and $n$ can be derived from (6):

$\mathrm{q}(\theta, \mathrm{n})=\frac{((\mathrm{n}-1) \theta+1) \mathrm{a}-\mathrm{c}}{\mathrm{nb}((\mathrm{n}-1) \theta+2)}$

The maximum individual firm profit as a function of $\theta$ and $n$ is:

$$
\begin{aligned}
& \pi_{\max }(\theta, \mathrm{n})=\frac{(((\mathrm{n}-1) \theta+1) \mathrm{a}-\mathrm{c})(\mathrm{a}-\mathrm{c})}{\mathrm{nb}((\mathrm{n}-1) \theta+2)} \\
& -\left(\frac{(((\mathrm{n}-1) \theta+1) \mathrm{a}-\mathrm{c})^{2}}{\mathrm{nb}((\mathrm{n}-1) \theta+2)^{2}}+\mathrm{k}\right)
\end{aligned}
$$

A numerical example indicates that the maximum of this function occurs where $\theta=0$ for all values of $\mathrm{n}$; we surmise but have not yet proven that this result generalizes to all price and cost functions. In the following graphs, $\mathrm{a}=800, \mathrm{~b}=10^{-8}, \mathrm{c}$ $=100$ and $\mathrm{k}=10^{6}$.

The LHS of Fig. 1 plots equilibrium maximum profit per firm as a function of the degree of strategic interaction $\theta$, in a 20 firm industry. The maximum profit clearly results from an interaction level of zero. By comparison, the Cournot-Nash recommended level $\left(\theta=\frac{1}{n E}\right)$ results in an equilibrium profit level per firm that is one fifth the level attained from no strategic interaction.

Since per firm output increases monotonically with $\theta$, it is also clear that output in excess of where $\theta=0$ is produced at a loss. 


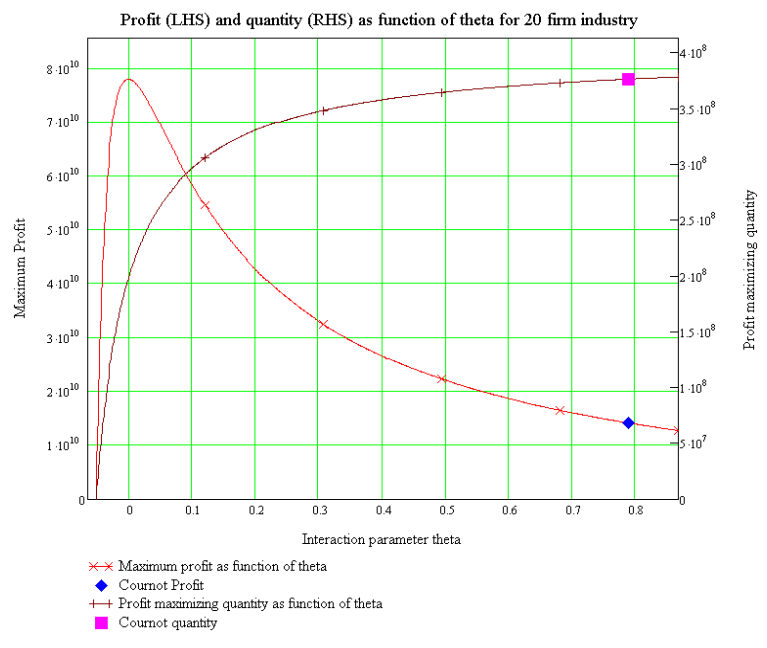

Fig. 1: Caption?

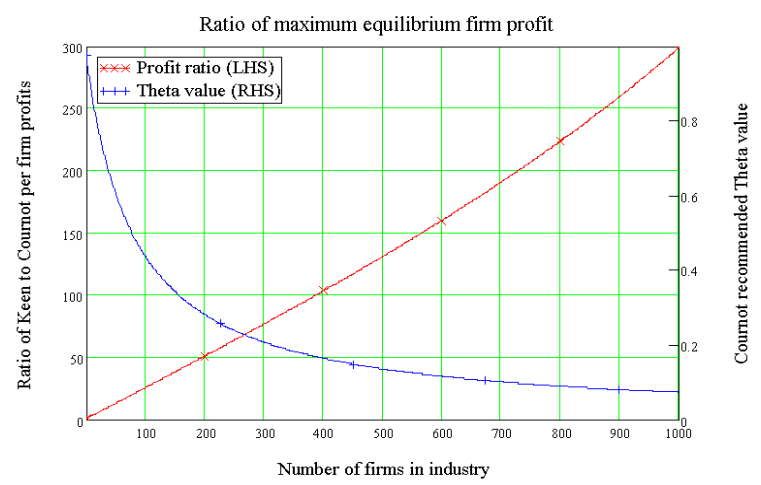

Fig. 2: Caption?

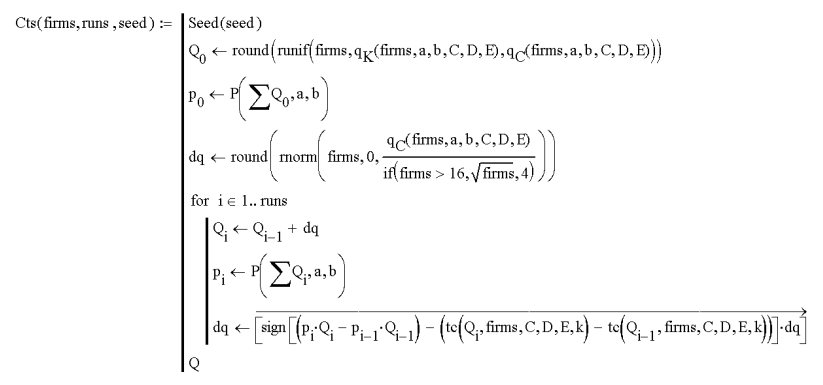

Fig. 3: Caption?

While marginal revenue as conventionally defined exceeds marginal cost until $\theta=\frac{1}{\mathrm{nE}}$, the revenue actually received by the firm (the total derivative of revenue) is below marginal cost.

Obviously, firms pay a large price for strategic interaction and Fig. 2 shows that this price rises as the number of firms in an industry increases.

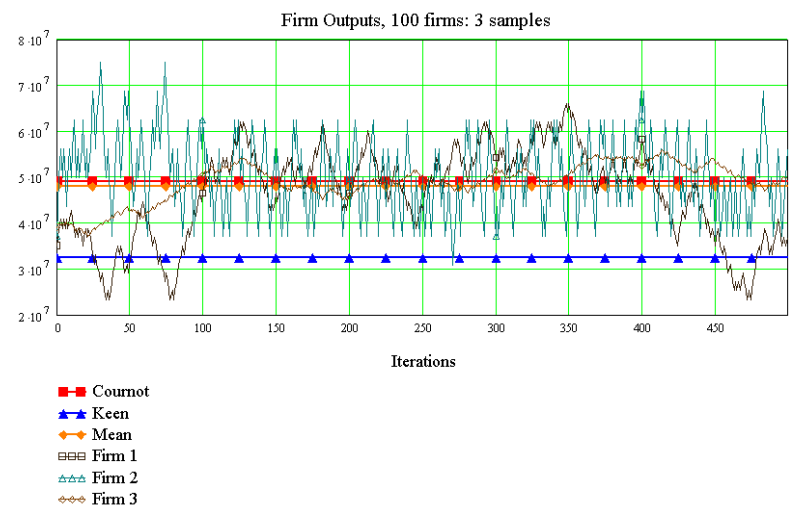

Fig. 4: Caption?

The LHS of Fig. 2 shows that the ratio of maximum profit per firm rises from a relatively low level for a small number of firms (1.125 for a duopoly; 2.042 for six firms) to extremely high levels for large numbers of firms-with 400 firms, equilibrium profit per firm without strategic interaction is over 100 times higher than with interaction at the Cournot-Nash level.

We thus have a dilemma: in industries where firms do not react strategically to the actions of others, firms achieve much higher profits than in those where strategic interaction does occur. What practice is likely to evolve in real-world markets?

We surmise that experience may teach firms that it is irrational to play the Cournot-Nash game. Instead, they may learn to simply ignore the hypothetical actions of other firms when deciding how much to produce. We consider this question using a multi-agent model of instrumentally rational profit maximizers facing comparable marginal cost functions.

Operationally rational profit-maximizers: Our hypothetical market has a linear demand curve $(\mathrm{P}=\mathrm{a}-$ bQ with $\mathrm{a}=800$ and $\mathrm{b}=10^{-7}$ ) and a variable number of instrumentally rational profit-maximizing agents. Each agent alters its output in a search for the profitmaximizing level of production; if a change in output in a given direction leads to an increase in profit, it continues to change output in that direction; otherwise it changes output in the other direction.

Total cost functions for the agents are identical and defined in a way that makes marginal costs from different numbers of firms strictly comparable: $\operatorname{tc}(\mathrm{q}, \mathrm{n})=\mathrm{k}+\mathrm{Cq}+\frac{1}{2} \operatorname{Dnq}^{2}+\frac{1}{3} \mathrm{En}^{2} \mathrm{q}^{3} \quad$ where $n$ is the number of fims, $\mathrm{k}=10^{6}, \mathrm{C}=10, \mathrm{D}=10^{-8}$ and $\mathrm{E}=$ $10^{-17}$. The reasons for the choice of this functional form are given in the Appendix. 


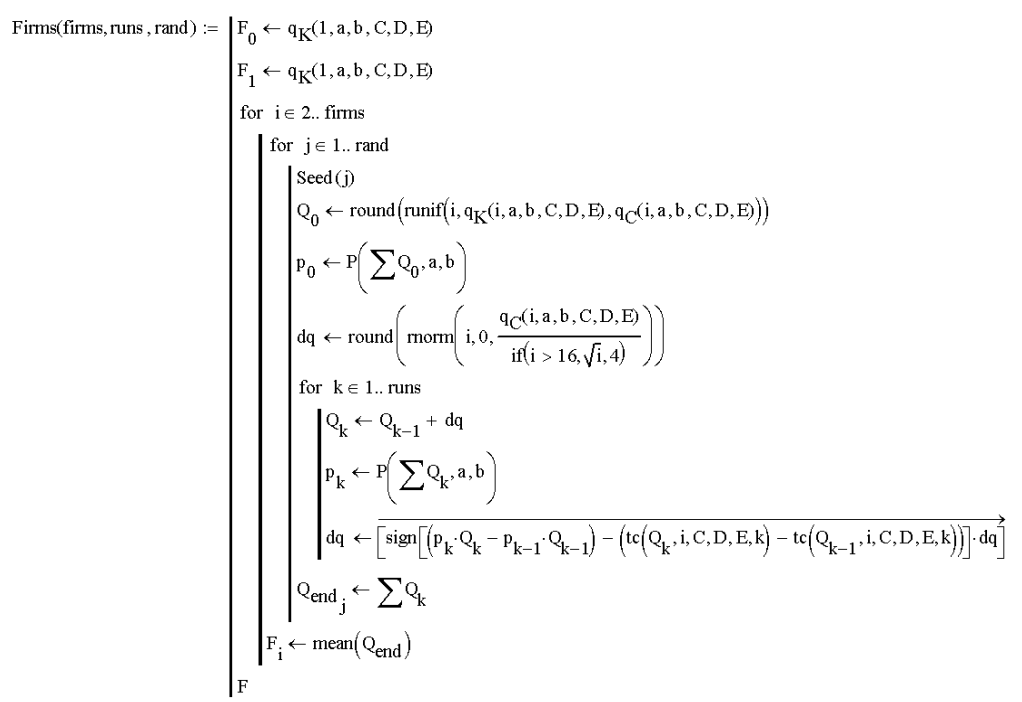

Fig. 5: Caption?

Firms start with a randomly determined initial output level that lies between the Keen and Cournot predictions and have a randomly determined amount by which output is varied.

\section{THE MODEL}

The basic program (written in the functional programming language of the mathematics package Mathcad) is shown in Fig. 1.

The program takes as its arguments the number of firms (firms), the number of iterations (runs) and a seed for a random number generator (seed). Working through the program line by line, the random number generator is seeded (1); an initial vector of outputs (2), a resulting market price (3) and vector of amounts to alter output (4) are determined; a loop is initialized (5); market output (6) and market price (7) are calculated for the $i^{\text {th }}$ iteration; firms decide whether to increase or decrease output depending on the impact of the previous change in output on profit (8). Finally a matrix storing each firm's output, at each iteration, is returned (9).

One key aspect of this simulation that may appear counter-intuitive to economists is that, despite the simplicity in the definition of agents and the fact that they have identical cost functions, the behavior of individual agents is extremely diverse. Figure 6 shows three sample firms from a 100 firm simulation, compared to the Keen and Cournot predictions. As is evident, the firms follow many different strategies. The complexity of individual behaviors emerges from the interactions between firms and the market, rather than from the innate "complexity" of the agents themselves.
The above sample simulation run comes close to the Cournot rather than the Keen outcome. However, a large number of random runs are required to provide an answer that is independent of initial conditions. The program shown in Fig. 5 implements a Monte Carlo simulation over a variable number of firms (starting from 2 ); it takes as arguments the maximum number of firms to consider (firms), the number of iterations to do for each market structure (runs) and the number of randomly seeded runs to do over each market structure (rand). It returns the average of the runs for each market structure.

Figure 6 shows the results for this program with between 2 and 500 firms, 4000 iterations per random run and 25 different runs. As we anticipated, the degree of competition does not rise smoothly as the number of firms increases, but instead peaks at a relatively small number of firms and then declines as the number of firms increases.

Price mirrors the quantity results: market price falls for a while as the number of firms increases, but then rises again once there are more than 30 firms in the industry. Competition improves consumer welfare only up to a point; beyond that level it reduces welfare.

Strategic interaction thus peaks at 30 firms, but then declines. Figure 8 shows the results of runs with 30 firms and 500 firms respectively against the theoretical predictions in Quantity/Price space. In contrast to the expectations of neoclassical theory, increasing the number of competitors results not in higher output and lower prices, but the reverse.

Irrationality and consumer welfare: Our analytic and simulation results show that hyper-rational profit-maximizing behavior does not guarantee the neoclassical outcome. 


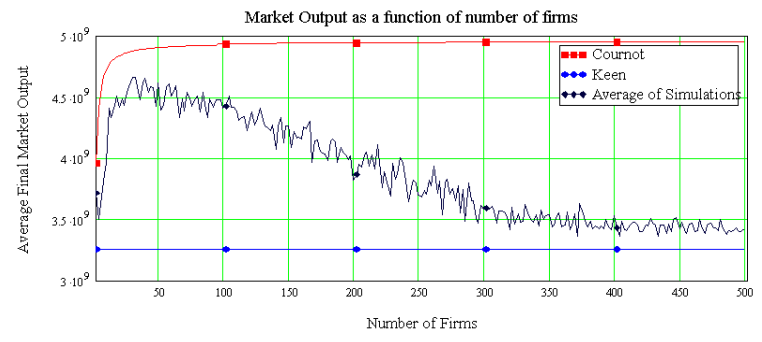

Fig. 6: Caption?

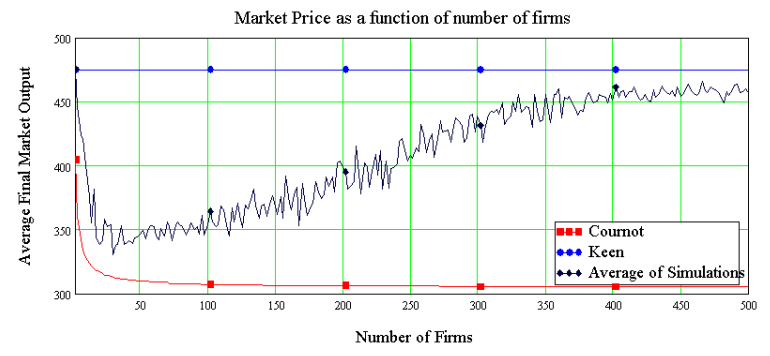

Fig. 7: Caption?

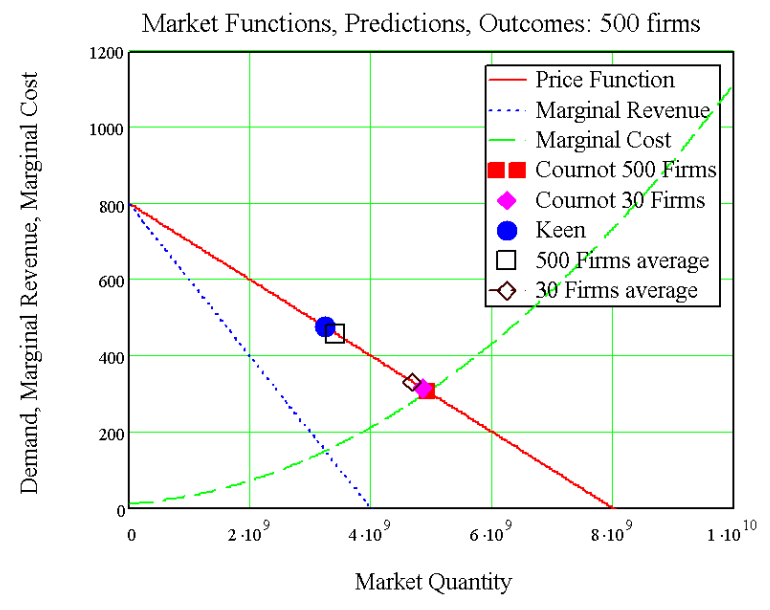

Fig. 8: Caption?

So if rationality won't do it, what about irrational behavior-acting in a manner that, on past experience, should reduce profit rather than increase it?

We consider this by seeding our simulation with the tendency for a fraction of firms to do the opposite to instrumentally rational behavior. It turns out that (a) the presence of irrational firms does cause industry output to converge to the Cournot output level, but (b) the degree of irrationality needed to achieve this is dependent upon the degree to which marginal costs rise with output.

The modified program needed to consider the impact of irrationality is shown in Fig. 9; the key change is the introduction of the expression runiff(firms, $-k,-k+1)$ into the $\operatorname{sign}()$ function in the output modification test. This produces a vector of random numbers between-k and 1-k. For $\mathrm{k}=0$, all these numbers are positive; for $\mathrm{k}=0.5$, on average half will be negative. On average then, $k \%$ of the firms in the industry will be irrational.

We ran this program with 30 firms and 400 firms, since the former was the level at which convergence to the Cournot equilibrium was most marked for rising marginal cost, while the latter was point where the trend towards the Keen equilibrium stabilized. Figure 10-13 show the average results with 4000 iterations per random run and 25 different runs, under conditions of both rising and constant marginal cost.

Figure 10 shows that only a small degree of irrationality is needed to guarantee the Cournot outcome for 30 firms facing rising marginal cost (including +/-two standard deviation error bars to indicate the degree of dispersal in the simulation runs). However the result was markedly unstable: once more than $6 \%$ of firms started to behave irrationally, the market "broke down".

Significantly more irrationality was needed under conditions of constant marginal cost to ensure the Cournot outcome-fifteen per cent of firms had to behave irrationally. However the result was markedly more stable than for rising marginal cost: the progression towards this position was smooth and stability applied out to $40 \%$ irrationality.

A similar, but substantially more stable pattern applied with 400 firms. Only a small degree of irrationality was needed to bring about the Cournot outcome with rising marginal cost and this result was comparatively robust for between $1 \%$ and $33 \%$ irrationality.

However, Fig. 13 shows that a much larger proportion of firms $(18 \%)$ need to be irrational in the case of constant marginal cost. On the other hand, the result was much more robust than for rising marginal cost, with stability of the Cournot equilibrium out to $49 \%$ irrationality-a strong result since this is just $1 \%$ from effectively random behavior (at which point, however, the system predictably ceased to have any attractor at all).

\section{CONCLUSION: AN INVERSE LINK BETWEEN RATIONALITY AND WELFARE}

Our research gives serious reason to reject the standard presumptions in economic theory that competition between rational profit-maximizing firms leads to a socially optimal outcome and that the more competition there is-or rather the more firms there arethe better is the outcome.

Firstly, simple but appropriate calculus shows that, in the absence of strategic interaction, firms maximize profit by producing where marginal revenue, as conventionally defined, greatly exceeds marginal cost. 


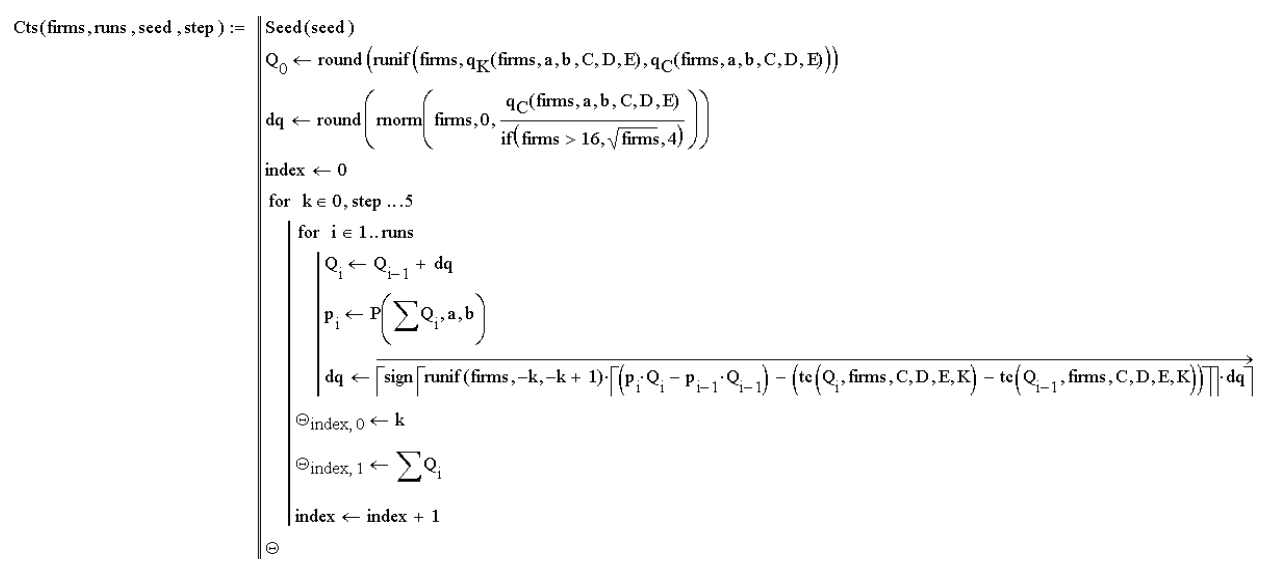

Fig. 9: Caption?

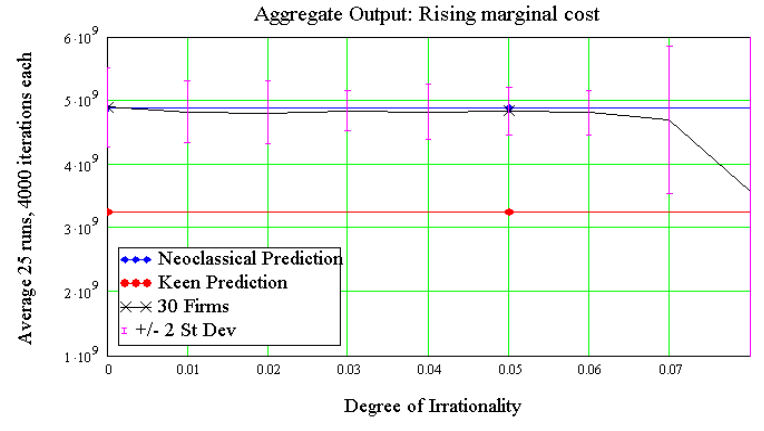

Fig. 10: Caption?

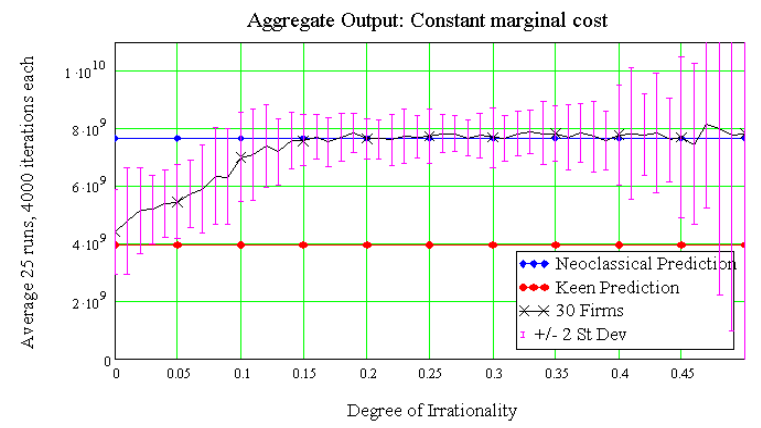

Fig. 11: Caption?

In the aggregate, the market output level is independent of the number of firms in the industry: Given comparable costs, an industry with a multitude of competitive firms will produce the same amount as a monopoly and the market price will be the same.

Secondly, strategic interaction does monotonically increase output and reduce profits, but strategic interaction by the $i^{\text {th }}$ firm makes no contribution to its own profit (If we replace the assumption that $\frac{\partial q_{i}}{\partial q_{j}}=\theta$ with the more general proposition that there is a unique reaction coefficient by each firm to each other firm, so that $\frac{\partial \mathrm{q}_{\mathrm{i}}}{\partial \mathrm{q}_{\mathrm{j}}}=\theta_{\mathrm{j}, \mathrm{i}}$ where $\theta_{\mathrm{j}, \mathrm{i}}$ is the reaction of the $j^{\text {th }}$ firm to a change in output by the $i^{\text {th }}$ firm, we find that $(\mathrm{n}-1) \theta$ in equation 6 is replaced by $\sum_{j \neq i}^{n} \theta_{j, i}$. Thus the strategic interaction terms in the $i^{\text {th }}$ firm's profit function are the sum of the reactions of other firms to what it does-its own reaction coefficients play no direct role in its own profits) and it appears that individual profit is maximized when firms do not strategically interact with each other. If we start from the proposition that firms are rational profit maximizers, it makes sense not to strategically interact at all-since interaction is costly, exponentially so for large numbers of firms and brings no benefits to the individual firm. Cournot-Nash games may, therefore, be rather like "Global Thermonuclear War" in the 1983 movie War Games: "A strange game. The only winning move is not to play".

Thirdly, effective competition-in terms of the maximization of market output and minimization of price-peaks at a moderate number of firms and falls after that (This result is dependent on rising marginal cost. As we show in Keen and Standish ${ }^{[3]}$, with constant marginal costs, convergence to the Cournot equilibrium does not occur for any industry structure.).

Finally, a degree of irrationality is needed for the Cournot outcome to apply in a population of artificial firms. The degree needed varies between a mere $1 \%$ under conditions of rising marginal cost (but with a very unstable system) and 20\% under conditions of constant marginal cost (with a very stable system). 


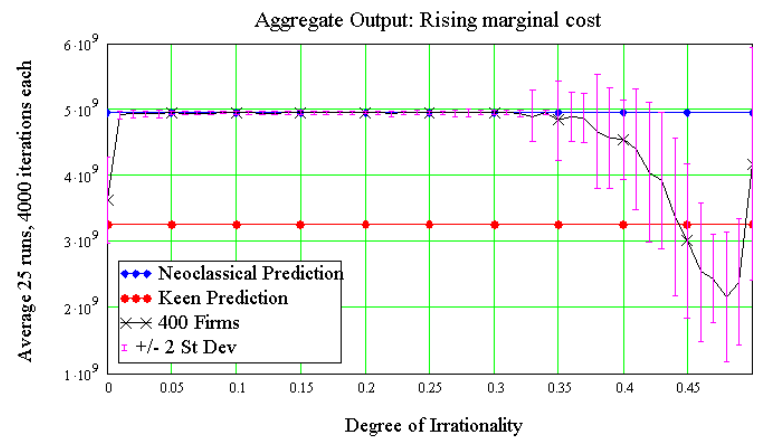

Fig. 12: Caption?

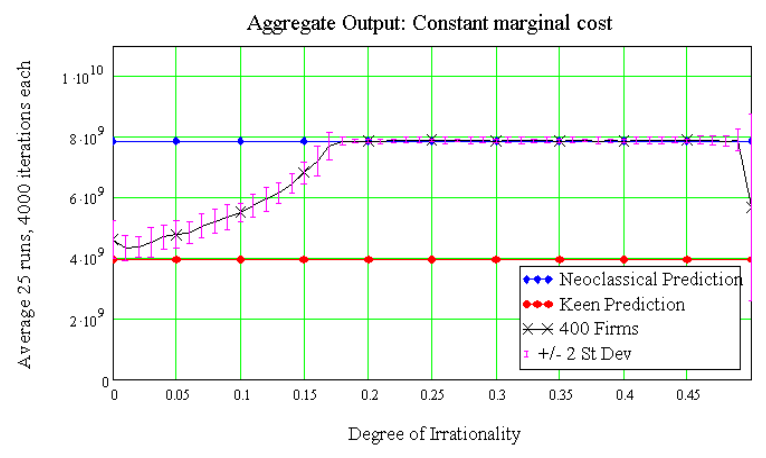

Fig. 13: Caption?

Whether this degree of irrationality exists in the real world is an empirical question-as is the issue of whether marginal cost is constant or rising for the majority of firms.

The evidence on both fronts is, with reference to the standard presumptions of economic theory, not good. Blinder et $a l^{[2]}$ is the latest and possibly most authoritative to conclude that the empirical data is "overwhelmingly bad news ... for economic theory...." ${ }^{[2]}\left(\mathrm{Lee}^{[4]}\right.$ for a comprehensive survey of preBlinder research and Downward and $\mathrm{Lee}^{[5]}$ for an accessible summary and interpretation of Blinder's findings). Eighty nine percent of firms in Blinder's survey reported marginal costs that were either constant or declined with output, while the data on demand elasticity led Blinder to ask rhetorically:

Can it really be true that firms that sell $40 \%$ of GDP believe that their demand is totally insensitive to price and that only about one-sixth of GDP is sold under conditions of elastic demand $?^{[2]}$.

It thus appears that firms are, generally speaking, rational profit-maximizers-which as we have shown, means that output is nearer to the so-called "monopoly" level than the so-called competitive level-and that they operate under conditions that would require a substantial degree of irrational behavior to cause a larger, welfare-maximizing output level.

We are not arguing here that competition as it actually occurs in practice is not socially beneficial. Our criticism is directed instead at the false belief that rational profit-maximizing behavior and competition as defined by neoclassical economic theory will lead to a welfare-maximizing outcome-again, as defined by neoclassical theory.

There are many important aspects of real-world competition that neoclassical theory abstracts fromreduction in markups, product and process innovation to mention a few-that clearly make a "competitive" industry preferable to an uncompetitive one. However, our research shows that "competitive" cannot be monotonically related to the number of firms, even when competition is restricted simply to output levels and price.

Appendix: Comparable cost functions: In this appendix we explain the form used for our total cost functions, which is necessary if outputs from different hypothetical industry structures are to be comparable.

The standard graphical exposition of Marshallian theory draws a common "Supply" curve to represent both the marginal cost curve of a monopoly and the sum of the marginal cost curves of a "competitive" industry. In fact a single curve can be drawn for these two market structures only under three restrictive conditions: (a) the monopoly is created by taking over all the competitive firms; (b) constant identical marginal costs; and (c) differing marginal costs which happen to be a function of the number of firms in the industry and coincide when aggregated.

The first condition is trivial (and would, on our analysis, result in no significant change in behavior); the second and third are implemented in the simulations above. This section proves that comparability is in general not the rule and derives the two non-trivial conditions for comparability.

Taking condition (b) first, the identity of the aggregate marginal cost curves of two different market structures for all scales of aggregate market output $Q$ imposes the condition that marginal products are identical for all scales of inputs. This in turn means that the production functions of the two market structures can only differ by a constant. Taking labor as the variable input, output with zero units of labor will be zero, so this constant can also be set to zero; 
therefore the condition of identity of aggregate marginal costs commutes into the condition that the aggregate output of the two industry structures must be the same for all levels of input.

Using $f$ for the production function of $n$ firms in one industry structure, $g$ for the production function of $m$ firms in another, $x$ for the per firm labor input in the $n$-firm industry and $y$ for the per firm input in the $m$ firm industry, the condition is:

$$
n \times f(x)=m \times g(y) \text { where } n x=m y
$$

Subsituting $\mathrm{y}=\frac{\mathrm{nx}}{\mathrm{m}}$ into (18) and differentiating with respect to $n$ yields:

$$
f(x)=\frac{x}{m} \times g^{\prime}\left(\frac{n x}{m}\right)
$$

This gives us a second expression for $f$. Equating these two definitions and rearranging yields:

$\frac{g\left(\frac{n x}{m}\right)}{n}=\frac{x}{m} g^{\prime}\left(\frac{n x}{m}\right)$

Substituting back $\mathrm{y}=\frac{\mathrm{nx}}{\mathrm{m}}$ and rearranging yields an expression involving the differential of the $\log$ of $g$ :

$$
\frac{g^{\prime}(y)}{g(y)}=\frac{1}{y}
$$

Integrating both sides yields:

$$
\ln (g(y))=\ln (y)+c
$$

Thus $g$ is a constant returns production function:

$$
\mathrm{g}(\mathrm{y})=\mathrm{Cy}
$$

From $\mathrm{y}=\frac{\mathrm{nx}}{\mathrm{m}}$ it follows that $f$ is the same constant returns production function:

$$
f(x)=\frac{m}{n} C \frac{n x}{m}
$$

Thus if marginal costs are to be identical across any scale of industry and output, they must be constant and identical.

Condition (c) allows marginal costs to differ at different scales of output, but requires that they aggregate to the same level. In this case, costs at each level of output must be a function of the number of firms in the industry. The rule for aggregating marginal cost is that the cost of producing $q$ units where there are $m$ firms in the industry equals the cost of producing $Q$ units where $\mathrm{Q}=\mathrm{mq}$. When applied as a condition to ensure that the aggregate marginal cost curve for an $n$ firm industry is equivalent to that for an $m$-firm industry, the number of firms in a given industry structure must be part of the argument for marginal cost.

In the example used in this chapter, we began with an aggregate marginal cost function:

$\mathrm{MC}(\mathrm{Q})=\mathrm{C}+\mathrm{DQ}+\mathrm{EQ}^{2}$

We then derived the firm level marginal cost function that was consistent with this rule in an $n$-firm industry:

$\operatorname{mc}(q, n)=M C(n q)=C+D n q+E(n q)^{2}$

\section{REFERENCES}

1. Stigler, G.J., 1957. Perfect competition, historically considered. J. Politic. Econ., 65: 1-17.

2. Blinder, A.S., E. Canetti, D. Lebow and J. Rudd, 1998. Asking about Prices: A New Approach to Understanding Price Stickiness. New York: Russell Sage Foundation.

3. Keen, S. and R. Standish, 2006. Complex Behavior and Conditional Convergence to Keen or CournotNash Equilibria in a Population of Profitmaximizers. In: Handbook of Research on Nature Inspired Computing for Economy and Management, Rennard, J.P. (Ed.), Idea Group, New York (forthcoming).

4. Lee, F., 1998. Post Keynesian Price Theory. Cambridge: Cambridge University Press. Mathcad 13, Mathsoft; www.mathsoft.com.

5. Downward, P. and F. Lee, 2001. Post Keynesian pricing theory reconfirmed? A critical review of asking about prices. J. Post Keynesian Econom., 23: 465-483. 